\title{
GLL
}

Geomatics, Landmanagement and Landscape No. $4 \cdot 2019,145-154$

\section{STUDY OF THE METHOD FOR FOCAL LENGTH DETERMINATION IN DIGITAL CAMERAS}

\author{
Volodymyr Hlotov, Alla Hunina
}

\section{Summary}

The authors analysed the methods for determining the focal length in digital cameras (DC) and proposed a method, the implementation of which is to survey the correct triangular metal prism from the left and right points of the basis. Next, on the stereo pair of digital images obtained from the surveying, the corresponding coordinates of the points on the near and far edges of the prism are measured, and the focal length of the non-metric DC is determined. To test the method, the focal length of the Sony ILCE-7R and Canon EOS 450D cameras was determined. In order to establish the precision parameters of the method, the following parameters were taken into account: determining the accuracy of measurment on the basis of surveying, the accuracy of measuring the heights, the accuracy of calculation of the longitudinal parallax, the accuracy of calculating the difference between the parallaxes.

\section{Keywords}

unmanned aerial vehicle $\bullet$ digital non-metric camera $\bullet$ focal length

\section{Introduction}

The use of non-metric DC is highly relevant today, and their applications continue to be explored. Non-metric DC are used as surveying equipment installed on unmanned aerial vehicles (UAVs). But these non-metric DCs, unlike expensive metrics, need to be calibrated. Calibration of non-metric DCs is implemented with the aim of using it as a measuring instrument for aerial survey from an UAV, and for further metric processing of images taken by this camera. One of the calibration parameters is the determination of the focal length of the non-metric DC.

The issue of research and analysis of methods for determining focal length of nonmetric DCs is discussed in a number of papers. Below we will review and analyze some of them.

The paper [Hlotov 2012, 2018] provides a method for determining the focal length of a non-metric DC, according to which control measurement grid (CMG) is established from the lens of that non-metric DC at fixed distances, which are not located at infinity from the said lens. Then by coordinate values, horizontal and verti- 
cal angles, the equivalent focal distance is determined, from which conclusions are drawn about the real focal length of the non-metric DC. In this particular method, however, a total station is used, which greatly reduces the cost, efficiency and feasibility of the method.

In the paper [Hlotov 2015, 2018], focal lengths of non-metric DCs are determined as follows: CMG is set horizontally and filming is performed. Then, on the resulting image of the CMG, graphical construction is juxtaposed of a line segment, the dimensions of which coincide with the focal length of the non-metric DC. Nevertheless, in this method, the CMG is set horizontally, which makes it difficult to focus on the entire area of the subject of the photograph, since the coordinates of the points in the CMG are set at different distances relative to the main optical axis of the non-metric DC. This fact in turn reduces the accuracy of measurements on the digital images obtained, which leads to lowering the accuracy of determining the focal length of the camera being investigated.

One of the promising methods of calibration of images, which is available in our conditions, is a method based on determining the characteristics of the central projection of images and its distortion by images of a special stand or control area of the location, where the coordinates $X, Y, Z$ of a large number of points are determined.

In the paper [Sholomitskiy 2002], a place for a calibrated stand was chosen on the wall of one of the classrooms. Dimensions of the stand were $3200 \times 4800 \mathrm{~mm}(9 \times 13$ marks). On the wall, with a step equal to $40 \mathrm{~cm}$ in the nodes of the grid, metal marks were fixed, sized $45 \times 45 \mathrm{~mm}$. In order to solve the problem of calibrating the images, spatial coordinates $X, Y, Z$ of all points of the polygon must be known. Consequently, the first step in solving the task is to carry out measurements of the test stand, in order to find the coordinates of all marks in the conventional system. However, in this particular method, the creation of the stand itself complicates the way of calibrating the camera, and in the actual conditions of an aerial survey calibration will not be possible.

The calibration method [Tsai 1987, Zhang 1999, 2000] requires that a planar pattern be placed in different orientations (at least 2) in front of a DC. It is possible to move either the camera or the planar pattern. The motion does not necessarily need to be known. The distortion of the lens is modelled. After that, the elements of external orientation (EEO), the elements of internal orientation (EIO), and distortion the parameters are determined. Compared to classical methods, this method does not require the use of expensive equipment, but since the camera calibration occurs using a planar pattern, it should be noted that calibration will only be possible under laboratory conditions.

In the publication [Hlotov 2011,2013] a method is proposed according to which the photography of the CMG is taken; additionally, on the pivot device, a mirror is installed with the ability to deviate the image of the CMG into the camera lens. Subsequently, at the digital photogrammetric station (DPS) „Delta-2”, measurements of the corresponding coordinates of the intersection of the CMG on a digital image are carried out, whereby the horizontal and vertical angles are measured between the directions 
on the central and other intersections. According to the obtained data, the focal length is calculated. This method makesit possible to increase the adaptability, efficiency and accuracy, as well as reduce the cost of determining the focal length. However, it cannot be applied in short-wave photogrammetry, since it involves the removal of points of objects located at infinity for the DC lens.

The work [Mikheeva 2011, Hlotov 2018] considers the parameters of CPC lenses calibration, and the requirements that must be observed for obtaining qualitaty materials. The author notes that the passport of DC does not specify the range of focal lengths, but instead, the range of segments within which the CCD matrix can move to obtain a sharp image. The paper also provides formulas for determining the length of such segments as well as focal lengths. However, in order to calibrate the camera, more hyper focal distance is required, except when pictures at taken at close distances.

In the paper [Malyavskiy 2007, Hlotov 2018] photogrammetric calibration of DCs for the images of the test object is discussed. The method is based on photographing the tested object with two cameras from one point in space. In this case, the EIO of one camera should be known, and the distortion parameters can be disregarded, as they are very small. Photos taken using the camera with a known EIO are considered to be the reference. Determination of the EIO and the distortion parameters of the second camera is performed when comparing the received image with the reference. The disadvantage of the method is the complexity of the calibration, resulting from the need of having a reference camera with a known EIO and with small distortion parameters that can be disregarded.

In the patent [Hlotov 2010] considers the way of establishing the mark with a central cross-section with the possibility of its rotation in a vertical plane around the central cross-section, followed by recording the images of the mark in at least four positions, rotating it by $360^{\circ}$, and calculating the planned EIO for the coordinates of these intersections for each mark position. However, this method defines only the planned EIO, which limits the information about the DC, and it does not allow the determination of the planned elements and focal lengths simultaneously, which is especially important for aerial surveying by an UAV, since that reduces the accuracy of the calculation of spatial coordinates of the points of research objects.

Having reviewed the literary sources, it is convincingly clear that, firstly, the chosen subject of research is relevant today, which, moreover, is confirmed by a large number of publications devoted to this topic. Secondly, there is a need for further development of ways to determine the focal length, since there is an urgent need to increase productivity and reduce the cost of such methods. This is due to the fact that when using non-metric DC today, companies do not possess adequate nomenclature equipment relating to the research of photographic devices.

\section{Research objective}

The objective of this study is to investigate the developed method for determining the focal length of non-metric DC. 


\section{Methodology}

There are many ways to determine the focal length of a non-metric DC, but some of them require considerable time and unique nomenclature equipment. Therefore, the task is to develop cost-effective and mobile calibration methods for non-metric cameras.

The authors have previously developed a method for determining focal length [Hlotov 2017, 2017a, 2018]. However, in the aforementioned method, the CMG is used, which today serves as nomenclature equipment, because it is a component of optomechanical photogrammetric devices, which are practically discontinued. Therefore, in the following method of focal length determination, instead of CMG, a metallic correct triangular prism is used (Fig. 1) [Hlotov 2018a].

The following method uses a metallic right triangular prism instead of a CMG to determine the focal length. The use of a triangular prism as the subject of surveying provides an opportunity to increase the adaptability of the method. The main concern is to increase the accuracy of measurements, since the measurements are made stereoscopically, and this allows to increase the accuracy of monocular measurements as much as 1.4 times, and thus increase the accuracy of DC focal length determination.

The metallic right triangular prism is placed on a tripod stand so that one of the vertices is directed towards the optical axis of the non-metric DC, and the base is parallel to the basis of surveying. With the overhead level, it is brought to a horizontal position. On the horizontal stand of the second tripod, the carriage is mounted on which the non-metric DC is positioned at some distance from the previous tripod, so that the main optical axis coincides approximately with the central part of the prism face, and surveying from the left point of the basis is performed. Then the non-metric DC is adjusted, while using a micrometer, to the size of the basis of surveying, and the surveying is carried out from the right point of the basis. Next, on the stereo pair of digital images obtained from the surveying, the corresponding coordinates of the points on the near and far edges of the prism are measured, and the focal length of the non-metric DC is determined.

Figure 1 presents a graphical depiction of the method for determining the focal length of a non-metric DC.

Assuming that $S_{l} o_{l}=S_{r} o_{r}=f ; B C=h ; S_{l} S_{r}=B ; B C=h$

$$
\begin{gathered}
\frac{B}{p}=\frac{H}{f} \\
h=\frac{H \cdot \Delta p}{p+\Delta p}-\text { Brok's formula }
\end{gathered}
$$

According to formulas (1), (2) the focal length $f$ is determined:

$$
f=\frac{p_{0} h}{B \Delta p}\left(p_{0}+\Delta p\right)
$$


where:

$p_{0}$ - longitudinal parallax [abscissa difference: $\left(x_{l}-x_{r}\right)$ measured on the near edge of the prism],

$\Delta p$ - the difference of longitudinal parallaxes between measurements at the far and near edge of the prism,

$h$ - height of a triangular prism,

$B$ - basis of surveying.

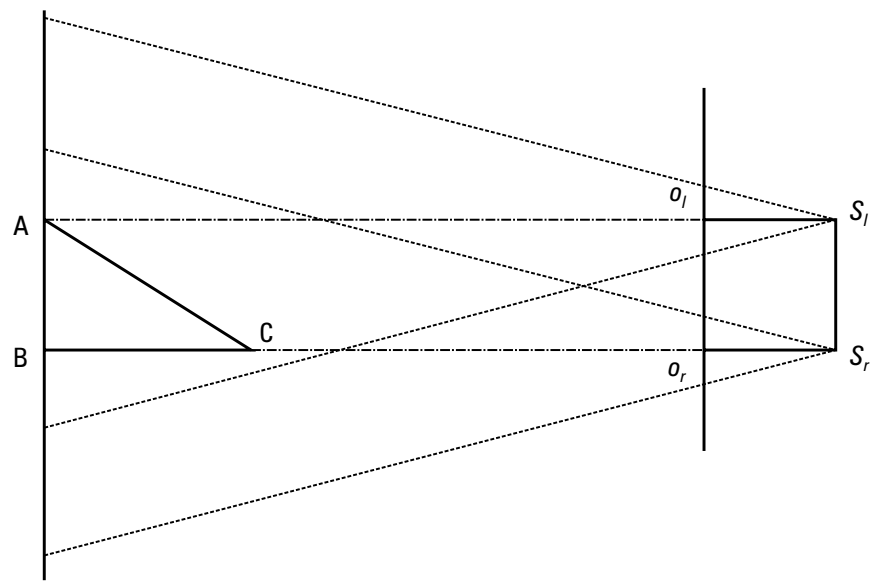

Fig. 1. Graphical representation of the method for determining the focal length of the DC, where: $S_{l} o_{l} S_{r} o_{r}$ - focal length, BC - height of a triangular prism, $A S_{l} B S_{l}$ - the main optical axes, $S_{r} S_{r}$ - base of surveying

Figure 2 presents a schematic illustration of the method for determining the focal length of a DC.

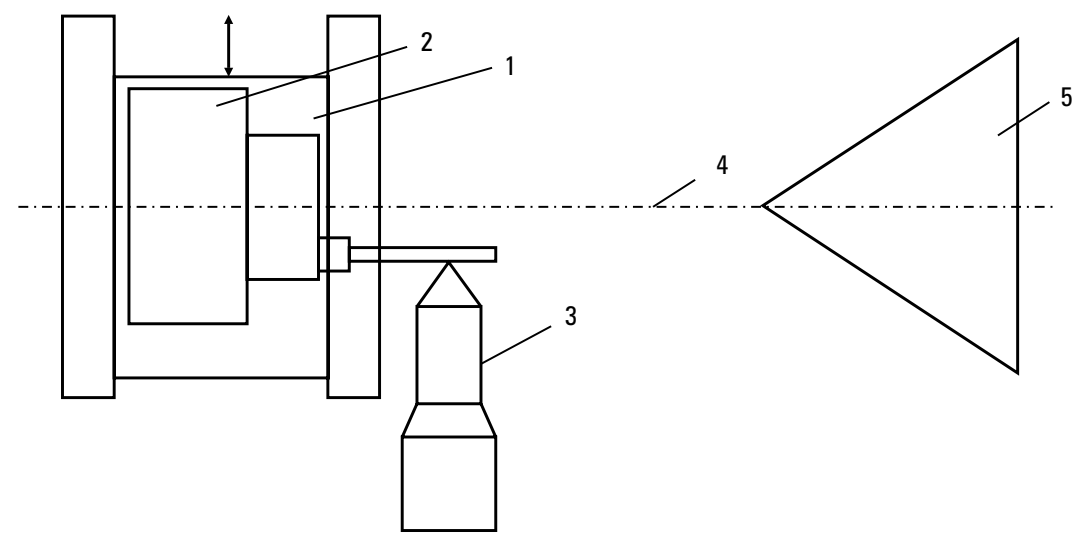

Fig. 2. Schematic location of devices, instruments and parts, where: 1 - carriage, 2 - DC, 3 - micrometer, 4 - the main optical axis, 5 - metallic right triangular prism 


\section{Investigation of the developed method for determining the focal length of DC}

The a priori estimation of the accuracy of determining the focal length is calculated using the formula (4), which was obtained from the formula (3):

$$
m_{f}=\left(\left(\frac{h(2 p+\Delta p)}{B \Delta p}\right)^{2} m_{p}^{2}+\left(\frac{p(p+\Delta p)}{B \Delta p}\right)^{2} m_{h}^{2}+\left(\frac{p h(p+\Delta p)}{B^{2} \Delta p}\right)^{2} m_{B}^{2}+\left(\frac{p^{2} h}{B \Delta p^{2}}\right)^{2} m_{\Delta p}^{2}\right)^{\frac{1}{2}}
$$

where:

$m_{B}-$ MSE of the measurement of the basis of surveying $(0.004 \mathrm{~mm})$,

$m_{h}$ - MSE of height measurement $(0.004 \mathrm{~mm})$,

$m_{p}-$ MSE of the calculation of longitudinal parallax $(0.002 \mathrm{~mm})$,

$m_{\Delta p}-$ MSE of the calculation of difference of the parallaxes $(0.004 \mathrm{~mm})$.

The results of the calculations of the a priori estimation of accuracy are presented in Table 1.

Table 1. A priori assessment of accuracy of focal length determination

\begin{tabular}{|l|c|c|}
\hline \multicolumn{1}{|c|}{ DC } & $f[\mathrm{~mm}]$ & $m_{f}[\mathrm{~mm}]$ \\
\hline Sony ILCE-7R & 35 & 0.007 \\
\hline Sony ILCE-7R & 25 & 0.007 \\
\hline Canon EOS 450D & 55 & 0.007 \\
\hline
\end{tabular}

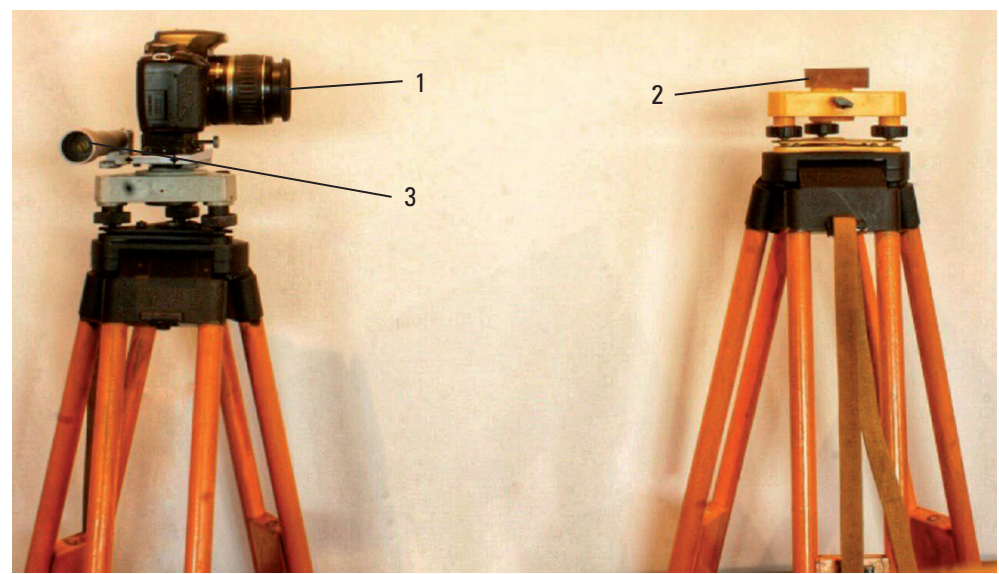

Fig. 3. Arrangement of devices and instruments in the method for determining the focal length of a DC, where 1 - DC, 2 - metal regular triangular prism, 3 - micrometer 
In order to test the method, the focal length of the Sony ILCE-7R and Canon EOS 450D cameras was determined.

The technological implementation of the method for determining the focal length non-metric DCs is presented in Figure 3.

\section{Results}

Focal length of a non-metric DC determined using the proposed method, and the a priori evaluation of the accuracy of focal lengthdetermination are shown in Table 2.

Table 2. The accuracy of the method for determining DC focal length

\begin{tabular}{|l|c|c|c|c|c|c|}
\hline \multicolumn{1}{|c|}{ DC } & $f[\mathrm{~mm}]$ & $B[\mathrm{~mm}]$ & $h[\mathrm{~mm}]$ & $p[\mathrm{~mm}]$ & $p[\mathrm{~mm}]$ & $f_{\text {defined }}[\mathrm{mm}]$ \\
\hline Sony ILCE-7R & 35 & 45 & 48.94 & 5.08 & 0.73 & 43.83 \\
\hline Sony ILCE-7R & 25 & 45 & 48.94 & 3.61 & 0.45 & 27.22 \\
\hline Canon 450D & 55 & 43.18 & 48.94 & 7.50 & 1.37 & 54.96 \\
\hline
\end{tabular}

The difference in focal length is explained by the movement of the extender of lens relative to focusing on the subject.

In order to verify the accuracy of the proposed method for determining focal length of a non-metric DC, a study was conducted taking into account all the instruments and details that make up the measuring complex. As a result, the following parameters have been detected, neglect of which leads to a significant decrease in accuracy:

1. Accuracy of measuring the basis of surveying

2. Accuracy of measuring the heights

$$
m_{B}=0.004 \mathrm{~mm}
$$

$$
m_{h}=0.004 \mathrm{~mm}
$$

3. Accuracy of measuring the calculation of the longitudinal parallax

$$
m_{p}=0.002 \mathrm{~mm}
$$

4. Accuracy of measuring the calculation of difference between the parallaxes

$$
m_{\Delta p}=0.004 \mathrm{~mm}
$$

Therefore, MSE of DC focal length determination will be presented as follows:

$$
\begin{gathered}
m_{f}=\sqrt{m_{B}^{2}+m_{H}^{2}+m_{p}^{2}+m_{\Delta p}^{2}} \\
m_{f}=0.007 \mathrm{~mm}
\end{gathered}
$$

\section{Scientific novelty}

The developed method, which provides the appropriate accuracy of determining the focal length, is investigated. 


\section{Practical significance}

At present, non-metric DCs are used as equipment for unmanned aerial vehicles (UAVs), and they are relatively inexpensive and quite common, unlike metric ones. These cameras were not designed by manufacturers for the use exclusively in aerial surveying, and therefore they have several disadvantages. The elements of internal orientation are not defined for such cameras with sufficient accuracy. However, in photogrammetry, focal length is a necessary part of mathematical processing of measurements, therefore the accuracy of determining this value directly affects the accuracy of determining the coordinates of terrain objects. There are many ways to identify elements of internal orientation of non-metric DCs, but some of them require considerable time and unique nomenclature equipment. Therefore, the authors propose a more economical and mobile way of calibrating a nonmetric camera. The method is intended for the applicatons in various fields of science and technology, such as the calibration of DC employed in topographic aerial surveying with the use of UAVs, which will improve the accuracy of determining the coordinates of the objects in the terrain.

\section{Conclusions}

After researching the method of determining focal length in DC, it should be noted that:

1. Method for determining focal length in DC is proposed, which can later be used to calibrate these cameras and to perform topographic aerial surveys with UAVs, which will improve the accuracy of determining the coordinates of terrain objects. The authors obtained a utility model patent [Hlotov 2018a].

2. The a priori estimation of the accuracy of the methods for focal length determination is calculated: $m_{f}=0.007 \mathrm{~mm}$.

3. Factors affecting the accuracy of focal length determination are investigated: the accuracy of measurement of the basis of surveying $m_{B}=0.004 \mathrm{~mm}$; the accuracy of measurement of heights $m_{h}=0.004 \mathrm{~mm}$; the accuracy of measurement of longitudinal parallax $m_{p}=0.002 \mathrm{~mm}$; the accuracy of measurement of difference between the parallaxes $m_{\Delta p}=0.004 \mathrm{~mm}$.

4. The purpose of further research would be to test the proposed method of focal length determination by different non-metric DCs, at different distances.

5. Publication is funded by the Polish National Agency for Academic Exchange under the International Academic Partnerships Programme from the project „Organization of the 9th International Scientific and Technical Conference entitled Environmental Engineering, Photogrammetry, Geoinformatics - Modern Technologies and Development Perspectives". 
Publication is funded by the Polish National Agency for Academic Exchange under the International Academic Partnerships Programme from the project "Organization of the 9th International Scientific and Technical Conference entitled Environmental Engineering, Photogrammetry, Geoinformatics - Modern Technologies and Development Perspectives".

\section{References}

Hlotov V., Hunina A., Yurkiv M. 2017. Method for determining the focal length in a digital non-metric camera. Geomatics, Landmanagement and Landscape, 3, 71-81.

Hlotov V., Hunina A. 2017a. Method of determination of digital camera focal length [Спосіб визначення фокусної віддалі цифрової знімальної камери]. Utility model patent, 121758 $\mathrm{UA}, 23$.

Hlotov V., Hunina A. 2018. Method of determining a digital camera focal length [Спосіб визначення фокусної віддалі цифрової знімальної камери]. New Technologies in geodesy, land management, forest management and environmental management: Proceedings of the IX International Scientific and Practical Conference, Uzhgorod, 114-118.

Hlotov V., Hunina A. 2018a. Method of determination of digital camera focal length [Спосіб визначення фокусної віддалі цифрової знімальної камери]. Utility model patent, 130494 $\mathrm{UA}, 23$.

Hlotov V., Pashchetnyk O. 2010. Method of determination of internal orientation elements of digital cameras [Спосіб визначення фокусної віддалі цифрової неметричної знімальної камери]. Patent for invention, 50155.

Hlotov V., Pashchetnyk O. 2011. Method of determination of digital camera focal length [Спосіб визначення фокусної віддалі цифрової знімальної камери]. Patent for invention, $94376 \mathrm{UA}, 8$.

Hlotov V., Pashchetnyk O. 2012. Method of determination of digital non-metric camera focal length [Спосіб визначення фокусної віддалі цифрової неметричної знімальної камери]. Patent for invention, 99984 UA, 20.

Hlotov V., Pashchetnyk O. 2013. A linear method for determining the internal orientation elements of digital non-metric cameras [Лінійний спосіб визначення елементів внутрішнього орієнтування цифрових неметричних знімальних камер]. Geodesy, Cartography and Aerial Photography. Republican Interdepartmental Scientific and Technical Collection, 7, 71-76.

Hlotov V., Pashchetnyk O. 2015. Method of determination of digital camera focal length [Спосіб визначення фокусної віддалі цифрової знімальної камери]. Utility model patent, 107756 UA.

Malyavskiy B., Bykov L., Bykov V., Makarov A. 2007. Method of photogrammetric calibration of cameras [Способ фотограмметрической калибровки камер]. Patent for invention, $23088001 \mathrm{RU}, 28$.

Mikheeva A. 2011. About variable focal length [О переменном фокусном расстоянии]. Bulletin of Polotsk State University, Applied Sciences. Building, 16, 146-150.

Sholomitskiy A., Shatokhin A. 2002. Creating a test bench for digital cameras calibration [Создание испытательного стенда для калибровки цифровых камер]. Scientific Works of Donetsk State Technical Institute, ser. Mining and Geology, 45, 80-84, http://www.vuzlib. com.ua/articles/book/24457-Sozdanie_ispytatelnogo_stenda_/1.html 
Tsai R. 1987. A versatile camera calibration technique for high-accuracy 3D machine vision metrology using off-the-shelf TV cameras and lenses. IEEE Journal on Robotics and Automation, 3(4), 323-344.

Zhang Z. 1999. Flexible camera calibration by viewing a plane from unknown orientations. I ICCV, 99, 666-673.

Zhang Z. 2000. A flexible new technique for camera calibration. IEEE Transactions on pattern analysis and machine intelligence, 22 (11), 1330-1334.

Prof., D.Sc. Volodymyr Hlotov

National University Lviv Polytechnic

Institute of Geodesy

Department of Photogrammetry and Geoinformatics

Ukraine, Lviv, 12 Bandera str., 79013

e-mail: volodymyr.m.hlotov@lpnu.ua

Alla Hunina, engineer

National University

Lviv Polytechnic

Institute of Geodesy

Department of Photogrammetry and Geoinformatics

Ukraine, Lviv, 12 Bandera str., 79013

e-mail: alla.v.hunina@lpnu 